\title{
Effectiveness of Various Anthropometric Indices in Prediction of Cardiovascular Risk Among Adult Jains
}

\author{
Meenal Dhall, Shilpi Gupta, Monika Bhuker, Pankhuri Sharma and Satwanti Kapoor*
}

Department of Anthropology, University of Delhi, Delhi-110007, India

\begin{abstract}
The present study was conducted on Jain population residing in Delhi to elucidate the effectiveness of various anthropometric indices as cardiovascular risk. A cross sectional sample of 48 adult Jain females (mean age $=50.5 \mathrm{yr}$ ) and 62 adult males (mean age $=47.4 \mathrm{yr}$ ) was studied. Various anthropometric and physiological measurements were taken on each subject. In the present study BMI was found to be a greater risk factor for cardiovascular health among Jain females supported by strong correlation of BMI with blood pressure [SBP, $\mathrm{p}<0.01$ and DBP, $\mathrm{p}<0.001]$, by high ' $\beta$ ' values [ $\beta$ $=0.578$ for $\mathrm{SBP}$ and $\beta=0.762$ for $\mathrm{DBP}$ ] and by high odds ratio for hypertension [2.3 times more for DBP]. The waist height ratio was found to be a good cardiovascular risk-screening tool among adult Jain males as revealed by a significant positive association of WHtR with blood pressure [DBP, $\mathrm{p}<0.05]$, by high ' $\beta$ ' value $[\beta=0.526$ for SBP and $\beta=0.599$ for DBP] and by elevated odds ratio for hypertension [21.9 times more for SBP and 3.9 times more for DBP]. Our study clearly revealed the gender specificity and relative effectiveness of anthropometric indices in prediction of cardiovascular health among Jain adults [BMI in Jain females and WHtR in Jain males].
\end{abstract}

Keywords: CVD, BMI, central obesity, gender, adults.

\section{INTRODUCTION}

Cardiovascular disease (CVD) is nowadays the leading cause of death for men and women both in the developed and developing countries [1]. Although the prevalence of some CVD risk factors has decreased in economically developed countries, the corresponding prevalence has increased in economically developing countries like India [2, 3]. It is estimated that half of all cardiovascular deaths in India occur in the working-age population compared with about one quarter in high-income countries [4]. There are large disparities in cardiovascular mortality in India [5]. For men and women, cardiovascular risk is known to increase with age, smoking, hypertension and central obesity [3]. One of the main causes of CVD is high blood pressure (BP) (essential hypertension) and obesity [6].

Obesity has been found to be one of the crucial risk factors of cardiovascular diseases in the general population [7]. The prevalence of obesity is increasing in both developed and developing countries [8]. Mohan et al. [9] on the basis of available data on prevalence of obesity from different published studies reported the prevalence of obesity among adults in India to be ranging from 10 to 50 percent. An increase in obesity has also been reported with age $[10,11]$. The increased prevalence of overweight/obesity was found to be related to improved socioeconomic status and urbanization among Tangkhul Naga females [12].

Obesity has been known to be associated with various cardiovascular risks like hypertension, diabetes, dyslipidemia etc [13]. A significant positive correlation of BMI and WHR with blood pressure was found among affluent Punjabi

*Address correspondence to this author at the Department of Anthropology, University of Delhi, Delhi-110007, India; Tel: 09810249131;

E-mail: satwanti@yahoo.com girls of Delhi [14].There are various anthropometric indices which define obesity with relative ease and accuracy like BMI (body mass index), WHR (waist hip ratio), WHtR (waist height ratio) and WC (waist circumference). Accumulating evidences have elucidated that BMI and WHtR can serve as valuable prognosticators for cardiovascular risk. A study conducted on Singaporean adult females demonstrated that WHtR can act as a best screening tool for cardiovascular risk [15]. Another study also reported that waist height ratio is a simple and effective screening tool for cardiovascular risk factors in both men and women [16]. WHR was reported to be secondary to BMI as a predictor of cardiovascular risk in Canadian adult men and women [17]. In Japanese men and women WHtR was found to be a better predictor of metabolic risk as compared to other anthropometric indices [18]. WHR acted as a risk factor for increased cardiovascular events and mortality in peritoneal dialysis patients in both males and females [19]. In Taiwanian adult males and females, an increase in BMI, WC, WHR and WHtR accounted for a higher risk of hypertension, diabetes, dyslipidemia and impaired fasting glucose [20]. BMI and WC showed a significant association with hypertension and WHR with Diabetes 2 among adult males in Chennai, India [21]. BMI and WC were reported to be useful screening tools among young obese women to detect early cardiovascular risk [22]. BMI was reported to be more detrimental to cardiovascular health among Aggarwal baniya females whereas among males it was WHR [23].

In a study conducted on the Saharia tribe, a vulnerable group, the indices of adiposity (WHR, WHtR, and BMI), fat percentage and blood pressure were found to be higher among pre diabetic males [24]. The primary objective of the present study was to assess the relative effectiveness of various anthropometric indices in prediction of cardiovascular risk among Jain population. 


\section{METHODS}

The Jains are the last direct representatives of the Shramana tradition in India. A shramana is a wandering monk in certain ascetic traditions of ancient India, including Jainism and Buddhism. Famous śhramana include religious leaders Mahavira and Gautama Buddha. They follow Jainism, as the dharma taught by the 24 Tirthankaras, the last of whom was Mahavira. The Jains have the highest literacy rate, 94.1\% compared with the national average of $65.38 \%$. They have the highest female literacy rate, $90.6 \%$ compared with the national average of $54.16 \%$. It is believed that the Jains also have the highest per capita income in India. The Jain population in India is 4,225,053 out of the total population of India $1,028,610,328$. Delhi consists of 155,122 of the total Jain population of India [25]. The community, comprising mostly of businessmen, traces their lineage to Lord Adinath, a seerking who preached non-violence, tolerance, vegetarianism and the importance of karma and literacy during the Vedic age (2nd-6th century B.C.). The members of the Jain community in the Indian capital are traditionally jewelers by profession. The Jain community is known for its social work and service in the sphere of education. The Jain communities, who don't like to be clubbed with Hindus, have their own temples, texts, religious mores, food habits and deities. Like Buddhism, the group is divided into two sects - the Shwetambar and Digambar folds. Many castes of the Jains are divided into two groups-visa and dasa. These groups are endogamous and the position of the later group is lower than that of the former. The members of the later group are not even allowed to enter the temples in some places, even though unsociability practically does not exist amongst Jains.

A cross sectional study was conducted on 110 adult Jains (48 females, 62 males, ranging in age from30-60 year) in Delhi. All the subjects volunteered for the study and gave written informed consent prior to the study. Various anthropometric measurements including height, weight, waist circumference, hip circumference and physiological dimensions like blood pressure, pulse rate and grip strength were taken on each subject. None of the subjects were measured immediately after ingesting their breakfast .Prior to taking physiological measurements, each subject was given 30 minutes of rest. The maximum grip strength of both the hands, right and left was taken with the help of dynamometer to assess the muscular strength. The mean of the maximum right and left hand grip strengths was used in the study and has been referred to as average grip strength. A standard prototype was followed while taking measurements [26]. Various anthropometric indices like BMI (weight/height ${ }^{2}$ ), WHR (waist circumference/hip circumference) and WHtR (waist circumference/height) were calculated. BMI was grouped according to the proposed criteria of WHO (under weight $<18.5$, normal- 18.5-24.5, overweight- 25.0- 29.9 and obese $\geq 30.0$ ) [27]. In the present study all the subject $\geq 30$ BMI have been considered as obese instead of different stages of obesity. Gender specific cut offs for abdominal obesity defined by $\mathrm{WC}$ (WC $\geq 90 \mathrm{~cm}$ in men and $\mathrm{WC} \geq 80 \mathrm{~cm}$ in women) [28] and of WHR (WHR $>0.95$ in males and WHR $>0.80$ in females) [29] were used. Waist height ratio of $\geq 0.5$ is considered to be a risk in both males and females [30]. Normal blood pressure was taken as $<120 \mathrm{mmHg}$ (systolic) and $<80 \mathrm{mmHg}$ (diastolic). Blood pressure values of $120-139 \mathrm{mmHg}$ (systolic) and $80-89 \mathrm{mmHg}$ (diastolic) were classified as pre- hypertensive. Stage-I hypertension was taken as $140-159 \mathrm{mmHg}$ (systolic) and $90-99 \mathrm{mmHg}$ (diastolic), whereas blood pressure of $>160 \mathrm{mmHg}$ (systolic) and $>100 \mathrm{mmHg}$ (diastolic) were classified as stage II hypertension [31].

The statistical analysis of the data was done with the help of SPSS version 16 . The analysis was done to see the association between different anthropometric indices and cardiovascular factors. The mean, standard deviation correlation coefficients, and chi square, $\beta$ values(linear regression) and odds ratio (OR) were computed.

\section{RESULTS}

Table 1 shows the general characteristics of the subjects. Jain males were taller, had greater grip strength, larger

Table 1. Basic Characteristics of Adult Jains

\begin{tabular}{|c|c|c|}
\hline Measurements & Females & Males \\
Mean \pm SD & $154.6 \pm 6.90$ & $166.2 \pm 9.97$ \\
\hline \hline Height $(\mathrm{cm})$ & $65.2 \pm 14.69$ & $70.2 \pm 15.21$ \\
\hline Weight $(\mathrm{kg})$ & $21.6 \pm .4 .97$ & $35.1 \pm 9.83$ \\
\hline Average Grip strength $(\mathrm{kg})$ & $133.2 \pm 5.63$ & $132.9 \pm 16.43$ \\
\hline Systolic blood pressure $(\mathrm{mmHg})$ & $81.6 \pm .38$ & $84.3 \pm 10.52$ \\
\hline Diastolic blood pressure $(\mathrm{mmHg})$ & $82 . \pm 0.31$ & $83.7 \pm 8.76$ \\
\hline Pulse rate $(\mathrm{bpm})$ & $80.2 \pm 12.18$ & $87.3 \pm 12.28$ \\
\hline Waist circumference $(\mathrm{cm})$ & $100.3 \pm 10.90$ & $95.5 \pm 9.13$ \\
\hline Hip circumference $(\mathrm{cm})$ & $27.3 \pm 5.95$ & $25.2 \pm 3.93$ \\
\hline Body mass index $\left(\mathrm{kg} / \mathrm{m}^{2}\right)$ & $0.8 \pm 0.06$ & $0.9 \pm 0.07$ \\
\hline Waist hip ratio & $0.5 \pm 0.07$ & $0.5 \pm 0.06$ \\
\hline Waist height ratio & & \\
\hline
\end{tabular}


Table 2. Association of Adiposity Indices and Cardiovascular Factors Among Adult Jains

\begin{tabular}{|c|c|c|c|c|c|c|}
\hline \multirow{2}{*}{ Measurements } & \multicolumn{3}{|c|}{ Females } & \multicolumn{3}{c|}{ Males } \\
\cline { 2 - 6 } & $\begin{array}{c}\text { SBP } \\
(\mathbf{m m H g})\end{array}$ & $\begin{array}{c}\text { DBP } \\
(\mathbf{m m H g})\end{array}$ & $\begin{array}{c}\text { PR } \\
(\text { bpm) }\end{array}$ & $\begin{array}{c}\text { SBP } \\
(\mathbf{m m H g})\end{array}$ & $\begin{array}{c}\text { DBP } \\
(\mathbf{m m H g})\end{array}$ & $\begin{array}{c}\text { PR } \\
(\mathbf{b p m})\end{array}$ \\
\hline \hline Waist circumference(cm) & $0.30^{* *}$ & $0.32^{* * *}$ & $0.36^{* * *}$ & 0.03 & $0.19^{*}$ & $0.20^{*}$ \\
\hline Body mass index $\left(\mathrm{kg} / \mathrm{m}^{2}\right)$ & $0.28^{* *}$ & $0.33^{* * *}$ & $0.31^{* *}$ & 0.12 & 0.10 & 0.16 \\
\hline Waist hip ratio & $0.32^{* * *}$ & $0.21^{* *}$ & $0.33^{* * *}$ & 0.10 & 0.18 \\
\hline Waist height ratio & $0.35^{* * *}$ & $0.29^{* *}$ & $0.38^{* * *}$ & 0.15 & $0.24^{*}$ & $0.21^{*}$ \\
\hline Average grip strength(kg) & $-0.31^{*}$ & -0.08 & 0.001 & $-0.29^{* *}$ & -0.14 & -0.16 \\
\hline
\end{tabular}

$* \mathrm{p}<0.05, * * \mathrm{p}<0.01, * * * \mathrm{p}<0.001$.

waists, narrower hips and higher WHR values as compared to their counterpart Jain females. On the other hand Jain males had higher BMI, larger hips.

Table 2 shows the association of anthropometric indices and cardiovascular factors among Jain males and females. The waist circumference as an index of central obesity has been found to be significantly related with SBP $(\mathrm{p}<0.01)$, DBP and PR in females ( $\mathrm{p}<0.001)$. In females BMI was also positively correlated with SBP and PR $(\mathrm{p}<0.01)$, and with DBP $(\mathrm{p}<0.001)$ while WHR was significantly related with SBP and PR $(p<0.001)$ and DBP $(p<0.01)$. WHtR showed a positive but significant correlation with SBP and PR $(\mathrm{p}<0.001)$ and DBP $(\mathrm{p}<0.01)$ in Jain females. The average hand grip strength among Jain females was negatively correlated with SBP $(\mathrm{p}<0.01)$. On the other hand waist circumference and waist height ratio were found to be positively corre- lated with DBP and PR ( $<<0.05)$ among Jain males and the average hand grip strength was found to be negatively correlated with SBP $(\mathrm{p}<0.01)$.

The prevalence of overweight/obesity among Jain males and females is presented in Table 3 . The prevalence of under weight was more in males $(4.8 \%)$, so was of normal weight $(45.2 \%)$. More Jain females were overweight $(43.8 \%)$ and obese $(18.8 \%)$ as compared to Jain males (overweight $40.3 \%$; obese $9.7 \%$ ).

Table 4 reflects the prevalence of hypertension among Jain males and females. The prevalence of pre hypertension was more in males $(\mathrm{SBP}=51.6 \%, \mathrm{DBP}=37.1 \%)$ as compared to females $(\mathrm{SBP}=37.5 \%, \mathrm{DBP}=18.8 \%)$ whereas stage I hypertension was more prevalent among females $(\mathrm{SBP}=35.4 \%$, $\mathrm{DBP}=18.8 \%)$ than males $(\mathrm{SBP}=21 \%, \mathrm{DBP}=14.5 \%)$ and stage II hypertension was more prevalent among adult Jain

Table 3. Prevalence of Overweight/Obesity Among Adult Jains

\begin{tabular}{|c|c|c|}
\hline \multirow[t]{2}{*}{ Body mass index $\left(\mathrm{kg} / \mathrm{m}^{2}\right)$} & \multicolumn{2}{|c|}{ Percentage } \\
\hline & Females & Males \\
\hline Normal weight & 35.4 & 45.2 \\
\hline Underweight & 2.1 & 4.8 \\
\hline Over weight & 43.8 & 40.3 \\
\hline Obese & 18.8 & 9.7 \\
\hline
\end{tabular}

Table 4. Prevalence of Hypertension Among Adult Jains

\begin{tabular}{|c|c|c|c|c|}
\hline \multirow[t]{3}{*}{ Blood pressure categories } & \multicolumn{4}{|c|}{ Percentage } \\
\hline & \multicolumn{2}{|c|}{ Females } & \multicolumn{2}{|c|}{ Males } \\
\hline & $\begin{array}{c}\text { SBP } \\
(\mathbf{m m H g})\end{array}$ & $\begin{array}{c}\text { DBP } \\
(\mathbf{m m H g})\end{array}$ & $\begin{array}{c}\text { SBP } \\
(\mathrm{mmHg})\end{array}$ & $\begin{array}{c}\text { DBP } \\
(\mathbf{m m H g})\end{array}$ \\
\hline Normal & 22.9 & 60.4 & 19.4 & 38.7 \\
\hline Pre hypertension & 37.5 & 18.8 & 51.6 & 37.1 \\
\hline Stage I hypertension & 35.4 & 18.8 & 21 & 14.5 \\
\hline Stage II hypertension & 4.2 & 2.1 & 8.1 & 9.7 \\
\hline
\end{tabular}


Table 5. Prevalence of Regional Obesity Among Adult Jains

\begin{tabular}{|c|c|c|c|c|c|c|}
\hline \multicolumn{2}{|c|}{ Indices } & \multicolumn{2}{|c|}{ Normal } & \multicolumn{2}{|c|}{ Risk } & \multirow[t]{2}{*}{$\chi^{2}$} \\
\hline & & $\mathbf{n}$ & $\%$ & $\mathbf{n}$ & $\%$ & \\
\hline \multirow[t]{2}{*}{ Waist hip ratio } & Females & 26 & 54.2 & 22 & 45.8 & \multirow[t]{2}{*}{$6.64^{*}$} \\
\hline & Males & 48 & 77.4 & 14 & 22.6 & \\
\hline \multirow[t]{2}{*}{ Waist height ratio } & Females & 19 & 39.6 & 29 & 60.4 & \multirow[t]{2}{*}{0.07} \\
\hline & Males & 23 & 37.1 & 39 & 62.9 & \\
\hline \multirow[t]{2}{*}{ Waist circumference $(\mathrm{cm})$} & Females & 24 & 50.0 & 24 & 50.0 & \multirow[t]{2}{*}{1.03} \\
\hline & Males & 37 & 59.7 & 25 & 40.3 & \\
\hline
\end{tabular}

$* \mathrm{p}<0.05$.

males $(\mathrm{SBP}=8.1 \%, \mathrm{DBP}=9.7 \%)$ than their female counterpart $(\mathrm{SBP}=4.2 \%, \mathrm{DBP}=2.1 \%)$.

Table 5 shows the prevalence of regional obesity among Jain males and females. Females dominated males in the prevalence of central obesity with respect to WHR $(45.8 \%)$ and WC $(50 \%)$, using WHtR more males were in risk category $(62.9 \%)$ as compared to Jain females $(60.4 \%)$. Significant differences were observed for WHR in chi square test $(p<0.05)$ between the prevalence of risk in females and males.

Table 6 presents the best predictor ( $\beta$ value) of cardiovascular health from various anthropometric indices. It is clear from the table that BMI was found to be a better predictor of cardiovascular risk in females $(\beta=0.578$ for SBP and $\beta=0.762$ for DBP) while WHtR came out to be an independent predictor of cardiovascular risk in males $(\beta=0.526$ for SBP, $\beta=0.599$ for DBP and $\beta=0.228$ for PR).

Table 7 presents the risk (odds ratio) for cardiovascular health from obesity indices. The hypertension stage I and II have been pooled together for this analysis. The chances of prehypertension in overweight Jain adult females were 1.7 times more for SBP and 3.6 times more for DBP. Obese Jain females had 2.3 times more likelihood of being hypertensive for DBP. Among overweight adult Jain males the risk of being prehypertensive was 3.1 times more for SBP and among obese Jain males it was 2.9 times more for SBP. In Females who were in risk category according to the WHR cut offs were 34.9 times more prone to become hypertensive (DBP). Among adult males the risk of hypertension in- creased with increasing WHtR (21.9 times more for SBP and 3.9 times more for DBP), so was the risk of prehypertension (4.7 times more for SBP and 3.7 times more for DBP). .No such association was found among Jain females.

\section{DISCUSSION}

Anthropometric measurement based indices of general (BMI) and regional (WHR, WC, WHtR) obesity have been used in the present study to identify the index which is more strongly associated with subsequent cardiovascular risk among adult Jain males and females, a business community with sedentary lifestyle and rich food habits.

BMI is most commonly used measure of overweight, obesity as well as of CED (chronic energy deficiency) [32, 33] and has been found to be important risk factor for CVD [34]. In the present study also BMI was found to be a greater risk factor for cardiovascular health among Jain females supported by strong correlation of BMI with blood pressure, high ' $\beta$ ' value and high odds ratio for hypertension in obese females. Prevalence of both overweight and obesity was higher and of undernutrion was lower among Jain females as compared to males. Their enhanced BMI could be due more to fat mass than metabolically active muscle mass, and due to their sedentary life style. Another study conducted on Punjabi girls of Delhi also reported a positive association between BMI and blood pressure [14].

The positive relationship between body mass index (BMI) and cardiovascular disease (CVD) mortality has also been reported from large prospective cohort studies [34, 35].

Table 6. Predictors of Cardiovascular Risk Among Adult Jains

\begin{tabular}{|c|c|c|c|c|c|c|}
\hline \multirow[t]{3}{*}{ Measurements } & \multicolumn{6}{|c|}{$\beta$ value } \\
\hline & \multicolumn{3}{|c|}{ Females } & \multicolumn{3}{|c|}{ males } \\
\hline & SBP & DBP & PR & SBP & DBP & PR \\
\hline Body mass index $(\mathrm{kg} / \mathrm{m} 2)$ & 0.578 & 0.762 & 0.328 & 0.165 & -0.320 & -0.105 \\
\hline Waist hip ratio & 0.557 & 0.401 & 0.335 & 0.007 & -0.190 & -0.168 \\
\hline Waist height ratio & 0.323 & -0.769 & 0.195 & 0.526 & 0.599 & 0.228 \\
\hline Waist circumference $(\mathrm{cm})$ & -0.876 & 0.143 & -0.334 & -0.573 & 0.049 & 0.203 \\
\hline
\end{tabular}

The highest values are in bold. 
Table 7. Obesity Indices as Risk Factor (Odds Ratio) for Pre-Hypertension and Hypertension

\begin{tabular}{|c|c|c|c|c|c|c|c|c|c|}
\hline \multirow{4}{*}{$\begin{array}{l}\text { Obesity } \\
\text { indices }\end{array}$} & \multirow[t]{4}{*}{ Categories } & \multicolumn{8}{|c|}{ Odds ratio ( $95 \%$ confidence interval) } \\
\hline & & \multicolumn{4}{|c|}{ Females } & \multicolumn{4}{|c|}{ Males } \\
\hline & & \multicolumn{2}{|c|}{ SBP } & \multicolumn{2}{|c|}{ DBP } & \multicolumn{2}{|c|}{ SBP } & \multicolumn{2}{|c|}{ DBP } \\
\hline & & $\begin{array}{c}\text { Pre } \\
\text { hypertension }\end{array}$ & $\begin{array}{l}\text { Hyperten- } \\
\text { sion }\end{array}$ & $\begin{array}{c}\text { Pre } \\
\text { hypertension }\end{array}$ & $\begin{array}{l}\text { Hyperten- } \\
\text { sion }\end{array}$ & $\begin{array}{l}\text { Pre hyper- } \\
\text { tension }\end{array}$ & $\begin{array}{l}\text { Hyperten- } \\
\text { sion }\end{array}$ & $\begin{array}{c}\text { Pre } \\
\text { hypertension }\end{array}$ & $\begin{array}{l}\text { Hyperten- } \\
\text { sion }\end{array}$ \\
\hline \multirow[t]{3}{*}{ BMI } & Over-weight & 1.732 & -0.758 & 3.650 & -0.560 & 3.132 & 1.571 & -0.633 & 1.329 \\
\hline & obese & -0.519 & -0.148 & - & 2.301 & 2.878 & 1.420 & 1.250 & 2.082 \\
\hline & Normal & $0^{\mathrm{a}}$ & $0^{\mathrm{a}}$ & $0^{\mathrm{a}}$ & $0^{\mathrm{a}}$ & $0^{\mathrm{a}}$ & $0^{\mathrm{a}}$ & $0^{\mathrm{a}}$ & $0^{\mathrm{a}}$ \\
\hline \multirow[t]{2}{*}{ WHR } & Risk & -0.553 & 1.468 & -0.771 & 34.989 & .059 & -0.70 & 1.882 & 1.261 \\
\hline & Normal & $0^{\mathrm{a}}$ & $0^{\mathrm{a}}$ & $0^{\mathrm{a}}$ & $0^{\mathrm{a}}$ & $0^{\mathrm{a}}$ & $0^{\mathrm{a}}$ & $0^{\mathrm{a}}$ & $0^{\mathrm{a}}$ \\
\hline \multirow[t]{2}{*}{ WHtR } & Risk & - & - & 1.040 & 1.798 & 4.723 & 21.94 & 3.737 & 3.963 \\
\hline & Normal & $0^{\mathrm{a}}$ & $0^{\mathrm{a}}$ & $0^{\mathrm{a}}$ & $0^{\mathrm{a}}$ & $0^{\mathrm{a}}$ & $0^{\mathrm{a}}$ & $0^{\mathrm{a}}$ & $0^{\mathrm{a}}$ \\
\hline \multirow[t]{2}{*}{ WC } & Risk & - & - & -0.459 & -0.065 & -0.872 & 0.951 & 1.103 & 1.100 \\
\hline & Normal & $0^{\mathrm{a}}$ & $0^{\mathrm{a}}$ & $0^{\mathrm{a}}$ & $0^{\mathrm{a}}$ & $0^{\mathrm{a}}$ & $0^{\mathrm{a}}$ & $0^{\mathrm{a}}$ & $0^{\mathrm{a}}$ \\
\hline
\end{tabular}

$0^{\mathrm{a}}$ Reference category.

However in contrast negative correlation between BMI and myocardial infraction among South Indians males and females was reported [36]. Obesity status was found to be related to hypertension [23] and with dyslipidaemia [37]. In women obesity was found to be associated with cardiovascular diseases [38-40].

The high prevalence of pre hypertension and stage II hypertension was quiet evident in Jain males than females and it may be due to the occupational tension which comes with business competition. A majority of the males were in business and the females were homemakers.

On the other hand waist height ratio was found to be a good cardiovascular risk-screening tool among adult Jain males not BMI as illustrated by a significant positive relationship of WHtR with blood pressure, elevated odds ratio for hypertension and high $\beta$ value. Some investigations have concluded that, compared with BMI, waist height ratio was more strongly associated with cardiovascular risk factors $[41,42]$. Waist height ratio demonstrated the best model fit and strongest associations with cardiovascular diseases [43]. Aekplakorn et al. also reported that WHtR to be associated with adverse cardiovascular risk in men [44]. Cox et al. reported WHtR to be having stronger linear associations with log odds of CVD development than BMI in men as compared to women [45]. WHtR as a better predictor of LDL cholesterol levels and elevated total cholesterol levels has been reported among men [37]. WHtR adds significantly to CVD risk prediction over BMI and WG (waist girth) in men [46]. WHtR is an important index of central obesity, which is free from any bias due to hip width changes along with waist circumference of short and tall subjects.

Contrary to our findings and others BMI was found to be an independent predictor for metabolic syndrome in men whereas WHR had a strong correlation with metabolic syndrome in women [47]. However, to strengthen our finding,
WHR was found to be most weakly associated with cardiovascular variables among Jain females rendering it a poor risk for CVD among them.

The waist hip ratio was one of the most commonly used anthropometric measures to indicate a central obesity pattern and an increased risk of cardiovascular disease [48, 49, 14, $50,23]$. The Inter Heart Study also reflected that WHR had a stronger and graded association with myocardial infarction worldwide [7].

The present study clearly indicates that BMI (body mass index) in females and Waist height ratio in males proved to be a better predictor of cardiovascular risk among adult Jains as compared to other anthropometric indices. One of the probable reasons could be that an increase in the amount of fat with age may be more pronounced in females as compared to males [51]. BMI may not depict the detrimental mass in males as the increase in weight due to increase in fat mass is equalized by decrease in lean body mass such as muscle and mineral components $[52,53]$ so skin fold thicknesses should be incorporated with BMI so as to evaluate the relative subcutaneous fat mass as well as fat distribution pattern. In males intra-abdominal fat is equalized by decrease in subcutaneous fat $[51,54]$ so waist circumference can not be the sole criteria to define abdominal obesity without taking height into consideration as height may influence the fat distribution. Unlike BMI, WHtR takes into account the distribution of body fat in the abdominal region which has been shown to be more associated with cardiovascular risks than body weight [55]. Hence WHtR is a better predictor of CVD risk primarily among Asian males [56].

Despite the close association between the obesity measures and cardiovascular risk, there remains some controversy regarding the best anthropometric index in prediction of CVD as adiposity indices may be ethnicity specific in assessing CVD risk. It is evident by various studies among Asian 
and Caucasian populations where the most evidences for the differences currently exists [57]. India is a multicultural and multiethnic country where caste endogamy governs the mating pattern hence presenting a multitude of physique, some resembling South-East Asians, others being closer to Caucasians and some are mixed. Gender specificity, regarding cardiovascular health risk through anthropometric indices was also proved in many studies $[24,37,47]$. So this can be the reason for the heterogeneity of two different anthropometric indices in prediction of CVD risk among Jain males and females. Furthermore the later were more acclimatized to household work and were not involved in vigorous physical activities voluntarily or habitually thus disposing them to be more overweight/obese. The prevalence of obesity was also reported to increase with sedentary lifestyle among Tangkhul Naga women [12]. On the other hand Jain males being in business sector also had sedentary behaviour along with omnipresent anxiety which comes with business competition, not only predisposed them to prehypertension, it also increased the fat amount which might have exaggerated the already existing androidal fat pattern typical of males thus the relation of WHtR among males.

\section{ACKNOWLEDGEMENTS}

We are highly indebted to our participants for their cooperation and the entire staff of "Veer Yuva Sangathan". The help rendered by Ms Anumeha Chaturvedi during first phase of fieldwork is duly acknowledged.

\section{REFERENCES}

[1] McKay J, Mensah GA. The atlas of heart disease and stroke. Geneva: World Health Organization 2004; 112.

[2] Murray CJ, Lopez AD. Mortality by cause for eight regions of the world: Global Burden of Disease Study. Lancet 1997; 349(9061): 1269-76.

[3] WHO Information sheet - Cardiovascular diseases: prevention and control, WHO 2003.

[4] Greenberg H, Raymond SU, Leeder SR. Cardiovascular disease and global health: threat and opportunity. Health AFF (Millwood) 2005; W5: 31-51.

[5] Gupta R, Misra A, Pais P, Rastogi P, Gupta VP. Correlation of regional cardiovascular disease mortality in India with lifestyle and nutritional factors. Int J Cardio 2006; 108(3): 291-300.

[6] WHO. Obesity: Preventing and managing the global epidemic. WHO Technical Series 894. Geneva: WHO 2000.

[7] Yusuf S, Hawken S, Ounpuu S, et al. Obesity and the risk of myocardial infarction in 27,000 participants from 52 countries: a casecontrol study. Lancet 2005; 366: 1640-9.

[8] World Health Organization. Obesity - preventing and managing the global epidemic. WHO technical report series 894. Geneva: World Health Organization 1999.

[9] Mohan V, Deepa R. Obesity and abdominal obesity in Asian Indians. Indian J Med Res 2006; 123(5): 593-6.

[10] Tyagi R, Kapoor S, Kapoor AK. Body composition and fat distribution pattern of urban elderly females (Delhi, India). Coll Anthropol 2005; 29(1): 315-9.

[11] Sinha R, Kapoor S. Sensitivity of various skinfold sites to fat deposition in adolescent daughters and their mothers. Acta Biol Szeged 2007; 51(1): 21-5.

[12] Mungreiphy NK, Kapoor S. Socio-economic change as covariates of overweight and obesity among Tangkhul Naga tribal women of Manipur, North East India. J Biosocial sci 2010; 42(3): 289-305.

[13] Kopelman PG. Obesity as a medical problem. Nature 2000; 404: 635-43.

[14] Suman, Kapoor S. Blood pressure,waist to hip ratio and body mass index among affluent Punjabi girls of Delhi. Acta Med Auxol 2000; 32(3): 153-7.

[15] Pua YH, Ong PH. Anthropometric indices as screening tools for cardiovascular risk factors in Singaporean women. Asia Pac J Clin Nutr 2005; 14(1): 74-9.
[16] Ashwell M, Gibson S. Waist to height ratio is a simple and effective obesity screening tool for cardiovascular risk factors: analysis of data from the british national diet and nutrition survey of adults aged 19-64 years. Obes Facts 2009; 2: 97-103.

[17] Franklin MM, Pereira LH, Garner BAJ, Associations of body mass index and waist: hip ratio with hypertension. CMAJ 1986; 135: 313-20.

[18] Hsieh SD, Muto T, Yoshinaga H, et al. Waist-to-height ratio, a simple and effective predictor for metabolic risk in Japanese men and women. International Congress Series 2006; 1294: pp. 186-9.

[19] Winnie SS, Catherine MC, Scott BK, Peter JM, Trevor JW, Azim SG. Waist-to-hip ratio, cardiovascular outcomes, and death in peritoneal dialysis patients. Int J Nephrol 2010; 2010: doi:10.4061/ 2010/831243.

[20] Huang K.C, Lin W.Y, Lee L.T, et al. Four anthropometric indices and cardiovascular risk factors in Taiwan. Int J of Obes 2002; 26: 1060-8.

[21] Kaur P, Radhakrishnan E, Sankarasubbaiyan S, et al. A comparison of anthropometric indices for predicting hypertension and type 2 diabetes in a male industrial population of Chennai, South India. Ethnic Dis 2008; 18(1): 31-6.

[22] Kamath A, Nandini M, Kedilaya HP, D'Souza V. Relation of anthropometry to CVD risk factors in young obese women. Biomed Res 2005; 16 (2): 137-41.

[23] Gupta S, Kapoor S. 2010. Sex differences in the Blood Pressure levels and its association with obesity indices: who is at greater risk. Ethn \& Dis 2010; 20: (In press).

[24] Kapoor S, Tyagi R, Chaturvedi A, Kapoor AK. Emerging health threats among a primitive tribal group of Central India. JPHE 2010; 2: $13-9$.

[25] Census of India. Office of Registrar General and Census Commissioner, India, 2001.

[26] Weiner JS, Lourie JA. Practical human biology, New York: Academic Press 1981.

[27] WHO expert consultation. Appropriate body-mass index for Asian population and its implication for policy and intervention strategies. Lancet 2004; 363: 157-63.

[28] Dobbelsteyn CJ, Joffres MR, Maclean DR, Flowerdew G. A comparative evaluation of waist circumference, waist-to-hip ratio and body mass index as indicators of cardiovascular risk factors. The Canadian Heart Health Surveys. Int J Obes 2001; 25: 652-61.

[29] Willett WC, Dietz WH, Colditz GA. Guidelines for healthy weight. New Engl J Med 1999; 341: 427-34.

[30] Ashwell M. Waist to height ratio shape chart could predict the health risks of obesity in adults and children in all ethnic groups. Nutr Food Sci 2005; 35(5): 359-64.

[31] Joint National Committee (JNC) on the Prevention, Detection, Evaluation, and Treatment of High Blood Pressure. The seventh report of the joint national committee on the prevention, detection, evaluation, and treatment of high blood pressure: the JNC 7 report. JAMA 2003; 289: 2560-72.

[32] Kamadjeu RM, Edwards R, Atanga JS. Anthropometry measures and prevalence of obesity in the urban adult population of Cameroon: an update from the Cameroon Burden of Diabetes Baseline Survey. BMC Public Health 2006; 6: 228.

[33] Kapoor S, Tyagi R, Saluja K, Chaturvedi A, Kapoor AK. Nutritional Profile and Socio-Economic Status of Saharia, a Primitive Tribe of India. OAJ 2009; 6: 58-63.

[34] McGee DL. Body mass index and mortality: A meta-analysis based on person-level data from twenty-six observational studies. Ann Epidemiol 2004; 15: 87-97.

[35] Wilson PWF, D'Agostino RB, Sullivan L, Parise H, Kannel WB. Overweight and obesity as determinants of cardiovascular risk: The Framingham experience. Arch Intern Med 2002; 162: 1867-72.

[36] Meenakshisundaram R, Agarwal D, Rajendiran C, Thirumalaikolundusubramanian P. Risk factors for myocardial infarction among low socioeconomic status South Indian population. Diabetol Metab Syndr 2010; 26: 2-32.

[37] Bertsias G, Mammas I, Linardakis M , Kafatos A. Overweight and obesity in relation to cardiovascular disease risk factors among medical students in Crete, Greece. BMC Public Health 2003; 3: 3.

[38] Kannel WB. 1997. Effect of weight on cardiovascular disease. Nutrition 13: 157-8.

[39] Harris TB, Savage PJ, Tell GS, Haan M, Kumanyika, Lynch JC. Carrying the burden of cardiovascular risk in old age: associations of weight and weight change with prevalent cardiovascular disease, 
risk factors, and health status in the Cardiovascular Health Study. Am J Clin Nutr 1997; 66: 837-44.

[40] Ko GTC, Chan JCN, Woo J, et al. Simple anthropometric indexes and cardiovascular risk factors in Chinese. Int J Obes Relat Metab Disord 1997; 21: 995-1001.

[41] Hsieh SD, Muto T. The superiority of waist-to-height ratio as an anthropometric index to evaluate clustering of coronary risk factors among non-obese men and women. Prev Med 2005; 40: 216-20.

[42] Bosy-Westphal A, Geisler C, Onur S. Value of body fat mass vs anthropometric obesity indices in the assessment of metabolic risk factors. Int J Obes (Lond) 2006; 30: 475-83.

[43] Gelber RP, Gaziano JM, Orav EJ, Manson JE, Buring JE, Kurth T. Measures of obesity and cardiovascular risk among men and women. J Am Coll Cardiol 2008; 52: 605-15.

[44] Aekplakorn W, Pakpeankitwatana $\dagger$ V, Lee CMY, et al. Abdominal obesity and coronary heart disease in thai men. Obesity 2007; 15 : 1036-42.

[45] Cox BD, Whichelow MJ, Prevost AT. The development of cardiovascular disease in relation to anthropometric indices and hypertension in British adults. Int J Obes Relat Metab Disord 1998; 22(10): 966-73.

[46] Chumlea WC, Jurca R, LaMonte MJ. Waist-to-height ratio as a predictor of cardiovascular disease risk. Med Sci Sports Exerc 2006; 38(5): 424.

[47] Ho SC, Chen YM, Woo JLF, Leunga SSF, Lam TH , Janus ED. Association between simple anthropometric indices and cardiovascular risk factors. Int J Obes 2001; 25(11): 1689-97.

[48] Larsson B, Svardsudd K, Welin L, Wilhelmsen L, Bjorntorp P, Tibblin G. Abdominal adipose tissue distribution, obesity, and risk of cardiovascular disease and death: 13 year follow up of participants in the study of men born in 1913. Br Med J (Clin Res Ed) 1984; 288: 1401-4.
[49] Perry AC, Applegate EB, Allison MD, Jackson ML, Miller PC. Clinical predictability of the waist-to-hip ratio in assessment of cardiovascular disease risk factors in overweight, premenopausal women. Am J Clin Nutr 1998; 68(5): 1022-7.

[50] Esmaillzadeh A, Mirmiran P, Azizi F. Waist-to-hip ratio is a better screening measure for cardiovascular risk factors than other anthropometric indicators in Tehranian adult men. Int J Obes Relat Metab Disord 2004; 28(10): 1325-32.

[51] Hsieh SD, Yoshinaga H, Muto T, Sakurai Y. Anthropometric obesity indices in relation to age and gender in Japanese adults. Tohoku J Exp Med 2000; 191: 79-84.

[52] Forbes GB, Reina JC. Adult lean body mass declines with age: some longitudinal observations. Metabolism 1970; 19: 653-63.

[53] Cohn SH, Vartsky D, Yasumura S, et al. Compartmental body composition based on total-body nitrogen, potassium, and calcium. Am J Physiol 1980; 239: E524-E530.

[54] Borkan GA, Hults DE, Garza SG, Robbins AH, Wilbert CK. Age changes in body composition revealed by computed tomography. J Gerontol 1983; 38: 673-7.

[55] Cikim AS, Ozbey N, Sencer E, Molvalilar S, Orhan Y. Associations among sex hormone binding globulin concentrations and characteristics of the metabolic syndrome in obese women. Diabetes Nutr Metab 2004; 17: 290-5.

[56] Hsieh SD, Yoshinaga H. Waist/height ratio as a simple and useful predictor of coronary heart disease risk factors in women. Intern Med 1995; 34: 1147-52.

[57] Lee CMY, Huxley RR, Wildman RP, Woodward M. Indices of abdominal obesity are better discriminators of cardiovascular risk factors than BMI: a meta-analysis. J Clin Epidemiol 2008; 61: 64653 .

Received: October 15, 2010

Revised: November 10, 2010

Accepted: November 28, 2010

() Dhall et al.; Licensee Bentham Open.

This is an open access article licensed under the terms of the Creative Commons Attribution Non-Commercial License (http://creativecommons.org/licenses/by-nc/3.0/) which permits unrestricted, non-commercial use, distribution and reproduction in any medium, provided the work is properly cited. 